\title{
PROPOSIÇÕES E CONTROVÉRSIAS NO CONECTIVISMO
}

\section{(PROPOSITIONS AND CONTROVERSIES IN CONNECTIVISM)}

\author{
Marie Jane Soares Carvalho \\ Universidade Federal do Rio Grande do Sul (Brasil)
}

\section{RESUMO}

Analisam-se as ideias e as aplicações do projeto conectivista. Para o conectivismo o que é relevante são as novas condições e ecologia de aprendizagem que envolvem abundância de informação, redes e conectividade. Há proposições instigantes e inúmeros conceitos agregados à proposta conectivista que exigem discussão e pesquisa. Para o conectivismo, os conhecimentos inovadores advêm da propriedade de realizar combinações, fusões e superposições entre dados e informações que se encontram distribuídos livremente nos links, nós e rede. Mas esta é uma premissa questionável dada a natureza das escalas na rede. A divulgação do conectvismo ganha adeptos e críticos. As críticas ao conectivismo registram inconformidade com sua reivindicação de teoria da aprendizagem. A melhor aceitação ao conectivismo se encontra no seu enderaçamento à pedagogia, mas encontramos reservas e críticas na concepção e prática conectivista nos Massive Open Online Courses.

Palavras-chave: conectivismo, pedagogia conectivista, redes, laços fracos, MOOC.

\begin{abstract}
In this paper, we analyze the ideas and applications of the connectivist project. For connectivism, we focus on what is most relevant, namely the new conditions and ecology of learning, which encompasses 'information abundance', 'networks', and 'connectivity. In addition, research proposals and numerous concepts are added to the connectivist proposalall of which require discussion and analysis. In connectivism, innovative knowledge typically involves combinations, fusion, and overlapping of data and information, which can be freely found in links, nodes, and networks. This is a questionable assumption given the nature of network scales. However, the promotion of connectivism has won both fans and critics. For instance, critics of connectivism criticize its claim of 'learning theory'. On the other hand, the greatest acceptance of connectivism is found in its connection with pedagogy. In sum, there are both reservations and criticisms about the concept and practice of Massive Open Online Courses.
\end{abstract}

Keywords: connectivism, connectivist pedagogy, networks, weak ties, MOOC. 


\section{PROPOSIÇÕES}

Siemens (2004, 2005, 2006, 2008; Siemens e Conole, 2011) defende o conceito de conectivismo ao observar que nenhuma das teorias - behaviorismo, cognitivismo e construtivismo - satisfaz as novas condições de aprendizagem e a nova ecologia que envolve abundância de informação, pessoas, software e, sobretudo, redes e conectividade. Não é a mudança de estado do indivíduo que manifesta a aprendizagem nem mesmo é a experiência que a promove, segundo Siemens. É a auto-organização do sistema como um todo que envolve o indivíduo, inicia o processo com ele e se expande para fora do organismo singular. Como isso acontece é anunciado, mas não é esclarecido ${ }^{1}$.

O autor argumenta que o indivíduo, por si, não terá condições de suportar dados e informações que serão outorgados às redes e sua permanente conexão e reorganização. A ação do indivíduo será da ordem de buscar, agregar e avaliar a pertinência da informação para seus propósitos. E isso exigirá propor combinações inteligentes que serão realizadas por software em razão da impossibilidade para os sujeitos em lidar individual e solitariamente com a abundância de dados e informação. O conhecimento será derivado e provisório para o sujeito e para o conjunto da rede. Os nós da rede, seu peso valorativo e sua ascendência sobre outros nós manterão em circulação as ideias e a formação de novos conhecimentos.

Para Siemens (2005) os elementos renovadores e inovadores nas redes se encontram em laços fracos e não em laços fortes. Os laços fortes dos nós numa rede pressupõem que os sujeitos, os nós e a rede ou redes sustentam-se uns aos outros porque compartilham conhecimentos e informações que já estão integrados, no mínimo são similares neste espaço e momento. No estado em que os laços são fortes é menos provável o surgimento de inovação, tanto individual como coletiva. Voltarei a esta ideia na seguinte seção, na qual trago as discussões originais de Gravenotter (1983).

Siemens (2008), a partir da provocação de outro pesquisador, desenvolve o que considera único no conectvismo. Nesta abordagem, ele aponta as heranças de inúmeras teorias para o desenvolvimento do conectivismo. Entre estas estão as teorias de Vygotsky, Bruner, McLuhan, Papert, Wittgenstein e sua noção de compreensão negociada, a teoria da complexidade e conceitos como comunidades de prática, aprendizagem situada, cognição distribuída, etc. Ao mesmo tempo, ele argumenta que a compreensão, a coerência, o significado e a significação são elementos proeminentes no construtivismo e no cognitivismo, mas não para o conectivismo. O fluxo e a abundância de informação tornam estes conceitos críticos, 
mesmo que Siemens (2005) tenha, anteriormente, atribuído importância destacada à criação de significados e à experiência incorporando ao conectivismo as ideias que critica. A proposição do conectivismo é ambivalente e Siemens se esforça para tomar distância das teorias que crítica.

Para o autor Siemens (2008) o que faz o conectivismo imperativo é a sua emergência no contexto de caos, abundância, mudanças rápidas e diversidade. E neste contexto, o modelo representacional é o do cérebro e suas conexões neurais. A mesma estrutura de aprendizagem que cria conexões neurais pode ser encontrada no modo como nós conectamos as ideias e no modo como conectamos pessoas e fontes de informação.

Para o conectivismo, o conhecimento é definido como o reconhecimento de padrões particulares de relações que ocorrem na rede entre nós e "a aprendizagem é definida como a criação de novas conexões” (Siemens, 2008, p. 29). Esta concepção sob a perspectiva de abundância de informação fez com que Siemens imaginasse que seria impraticável ao sujeito coordenar as informações. A abundância de dados e informação exige que o sujeito saiba propor questões, manejar ferramentas que possam realizar análises e, deste modo, gerar compreensão e conhecimentos. $\mathrm{Ou}$ seja, a inteligência estaria fora do sujeito, pois ele não tem condições de manipular a crescente e infinita quantidade de informação e dados. Os sistemas e as ferramentas farão isso pelos sujeitos. A inteligência se desloca do sujeito particular para as redes, os nós nas redes e a construção de relações entre esses. Ele diz que "as conexões que nos permitem aprender são mais importantes do que o nosso estado atual de conhecimento" (Siemens, 2008, p. 30) numa clara referência e em contraposição às ideias construtivistas e construcionistas.

Tal perspectiva recupera o conceito de Lévy (1986) sobre inteligência coletiva, mas com outro entendimento. A inteligência humana se encontra nas conexões que pode suportar e com as quais pode trabalhar. Mas a compreensão e o conhecimento são da ordem coletiva, na qual o sujeito contribui com uma parte. Dada a quantidade existente de informação, a sua natureza fluída, instável em razão da sua produção e atualização constante, tornando obsoleto outro tanto de informação, o conhecimento só pode ser realizado de modo coletivo e conectado às redes. A inclusão da tecnologia tem papel relevante na distribuição da cognição, das identidades e do conhecimento. Adicionalmente a tecnologia trabalha para criar e mostrar padrões, extendendo e melhorando nossa habilidade cognitiva (Siemens, 2008). Estas são as premissas centrais sob as quais se assentam a proposta do conectivismo. 
Não se sabe como o sujeito chegará a distinguir os nós e as conexões importantes nem como ele fará para dispor as informações ou avaliar sua pertinência, mesmo com a ajuda de outros. Sem que se saiba fazer perguntas não existem dados nem informação. E para tanto é necessário que o próprio sujeito tenha formação que permita a ele ver o mundo e orientar-se na busca. Talvez, a pressuposição de Siemens e Downes implica que viver nas redes e participar de nós levaria os sujeitos a autorientarem-se para conhecer e produzir aquilo que lhes interessa unindose a outros. Ou que a própria rede e os sujeitos orientam-se mutuamente. Estas especulações surgem justamente pelo fato de que os arrazoados apresentados por ambos os autores são incompletos. Os registros esparsos, as elaborações tateantes, as agregações conceituais e os anúncios provisórios de Siemens e Downes constituem uma provocação que outros terão de buscar e completar para que o conectivismo reivindique uma posição de teoria. Como há profusão de conceitos nomeados no conectivismo, a tarefa de realizar aprofundamento requer ir separando-os e observar o que seus autores originais proporam e como isso nos ajuda a compreender melhor a aprendizagem em redes. Deter-me-ei somente em dois conceitos: redes e laços fracos.

\section{CONCEITOS AGREGADOS}

Os autores que Siemens nomeia, ou nomeou em algum momento, como exercendo influencia sobre o que ele pensa são inúmeros. Reproduzo parcialmente a síntese feita por Santamaría (2010) com os conceitos que respondem mais pela área da educação e pedagogia.

\begin{tabular}{|l|l|l|}
\hline \multicolumn{1}{|c|}{ Término } & \multicolumn{1}{|c|}{ Autores } & \multicolumn{1}{c|}{ Principios } \\
\hline $\begin{array}{l}\text { Red de } \\
\text { aprendizaje }\end{array}$ & $\begin{array}{l}\text { Pithamber R. } \\
\text { Polsani (2003), } \\
\text { sobre la base de } \\
\text { Letwork }\end{array}$ & $\begin{array}{l}\text { Una "forma de educación cuyo lugar de } \\
\text { producción es la red", es decir, que permite los } \\
\text { procesos de aprendizaje a lo largo de toda la } \\
\text { vida a través de conexiones y accesos a redes } \\
\text { en donde hay múltiples capas de información y } \\
\text { conocimiento. }\end{array}$ \\
\hline
\end{tabular}




\begin{tabular}{|c|c|c|}
\hline Término & Autores & Principios \\
\hline $\begin{array}{l}\text { La teoría del } \\
\text { Actor-Red o la } \\
\text { Ontología del } \\
\text { Actante-Rizoma }\end{array}$ & $\begin{array}{l}\text { Bruno Latour } \\
\text { (junto M. Callon y } \\
\text { John Law) hacia } \\
\text { 1991-1992 hicieron } \\
\text { una recopilación } \\
\text { para generar el } \\
\text { corpus teórico. }\end{array}$ & $\begin{array}{l}\text { La importancia de lo tecnológico en la explicación } \\
\text { del mundo, tratándolo de una manera equivalente } \\
\text { a la manera en que se trata lo social. Esta teoría } \\
\text { pone atención en las redes que se establecen } \\
\text { en la producción de conocimiento, estudiando } \\
\text { y observando el entorno de los ingenieros y } \\
\text { científicos cuando llevan a cabo sus proyectos, } \\
\text { enfatizando que nadie actúa solo y que hay un } \\
\text { gran número de actantes que influyen. El término } \\
\text { actante es utilizado como una forma neutral para } \\
\text { referirse a actores tanto humanos como no- } \\
\text { humanos, ya que sus principales creadores de } \\
\text { ANT han considerado que la palabra actor tiene } \\
\text { una carga simbólica ligada al "ser persona" (uno } \\
\text { de los principios conectivistas). }\end{array}$ \\
\hline E-learning 2.0 & Downes (2005) & $\begin{array}{l}\text { El contenido del aprendizaje se crea y distribuye } \\
\text { de forma muy diferente. En lugar de estar } \\
\text { compuesto, organizado y empaquetado, el } \\
\text { contenido de elearning se sindica, algo más } \\
\text { parecido a una entrada de blog o a un podcast. Los } \\
\text { estudiantes agregan sus propias herramientas } \\
\text { y aplicaciones. A partir de ahí, remezclan y } \\
\text { replantean en función de las propias necesidades } \\
\text { individuales de aprendizaje. }\end{array}$ \\
\hline Microlearning & $\begin{array}{l}\text { Hugh, Lander y } \\
\text { Brack (2006); } \\
\text { Lindner (2006) }\end{array}$ & $\begin{array}{l}\text { Un nuevo paradigma que incluye el aprendizaje } \\
\text { a través de unidades relativamente pequeñas } \\
\text { y actividades de aprendizaje a corto plazo. } \\
\text { Los procesos de microlearning se derivan } \\
\text { con frecuencia de la interacción con micro- } \\
\text { contenido, lo cual incluye pequeños trozos de } \\
\text { contenido y tecnologías flexibles que capacitan } \\
\text { a los estudiantes para el fácil acceso a ellos, en } \\
\text { cualquier parte, bajo demanda y gestión. En } \\
\text { sentido amplio, describe la forma en la que } \\
\text { la adquisición de conocimiento informal y } \\
\text { accidental está teniendo lugar de forma creciente } \\
\text { a través de micro-contenido, micro-media o } \\
\text { entornos multitarea, especialmente aquellos que } \\
\text { están basados en tecnologías web } 2.0 \text { y móviles. }\end{array}$ \\
\hline
\end{tabular}




\begin{tabular}{|c|l|l|}
\hline \multicolumn{1}{|c|}{ Término } & \multicolumn{1}{|c|}{ Autores } & \multicolumn{1}{|c|}{ Principios } \\
\hline Pedagogía 2.0 & $\begin{array}{l}\text { McLoughlin y Lee } \\
\text { (2007) }\end{array}$ & $\begin{array}{l}\text { Las nuevas herramientas digitales y posibilidades } \\
\text { demandan una nueva conceptualización de } \\
\text { la enseñanza cuyo foco de atención es la } \\
\text { participación en comunidades y redes de } \\
\text { aprendizaje, la personalización de tareas de } \\
\text { aprendizaje y producción de conocimiento. }\end{array}$ \\
\hline
\end{tabular}

Quadro 1. Síntese de autores e ideias relacionadas ao conectivismo Fonte: Santamaria (2010, p. vi-vii)

Uma das ideias mais comentadas por Siemens diz respeito a redes na qual a conexão entre múltiplas capas envolve sujeitos, dados, informações e subredes. Siemens busca a ideia de redes e conexão desenvolvidos por Barabási (2002). Há outros autores também nomeados por Siemens e identificados por Santamaria (Quadro 1), mas as ideias mais relevantes sobre conexão estão desenvolvidas por Barabási (2002). O autor demonstra como estamos todos conectados uns com os outros. O mundo interconectado existiu desde sempre, mas de modo diferente em cada tempo e de acordo com os meios, suportes e ferramentas disponíveis.

Uma das principais pesquisas de Barabási (2002) examina qual é a distância que separa as pessoas ao testar a hipótese dos seis graus de separação para concluir que vivemos numa rede social complexa ${ }^{2}$. Apesar disso e justamente por isso, este é um mundo pequeno e cada vez mais pequeno pela possibilidade de nos colocar mais rapidamente ao alcance de um com os outros e vice-versa. Estamos, hoje, a menos de seis graus de separação entre todos (Barabási, 2002; Watts, 2003). Somente quem vive isolado em algum povoado nos confins do mundo, encapsulado nos territórios de laços fortes, está a mais de seis graus de separação. E nem mesmo os confins do mundo estão realmente fora das possibilidades de conexão e de seis graus de separação ou menos.

Uma das teses centrais de Barabási (2002) é que a rede é um lugar onde a distribuição das possibilidades é desigual. Os nós mais antigos serão cada vez mais conectados em comparação com os nós novos (Figura 1), criando os hubs que têm grande poder sobre o conjunto de nós (Barabási, 2002). Ou seja, os nós ricos tornamse mais ricos. 


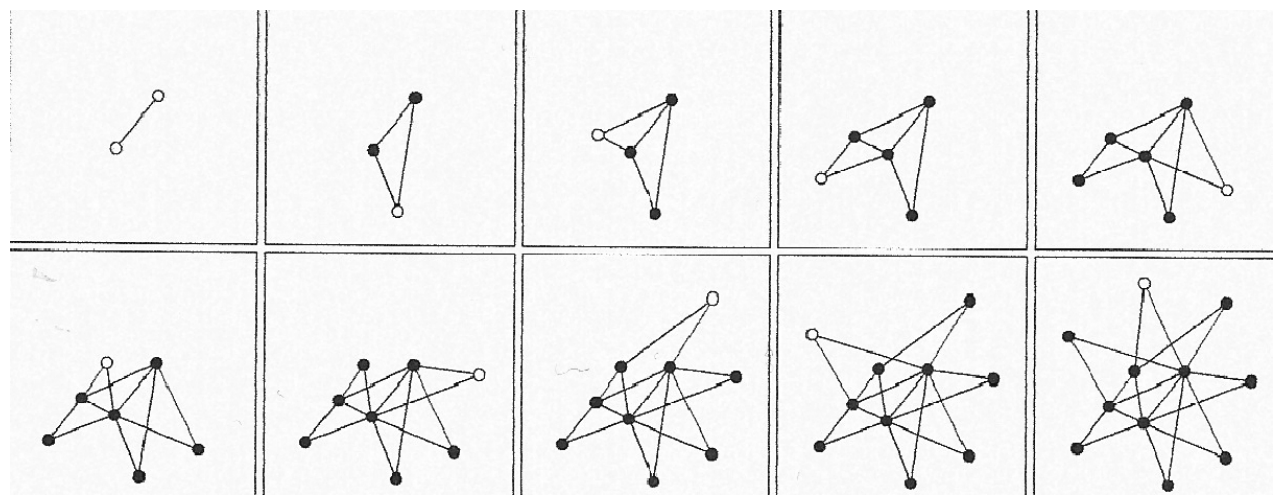

Figura 1. O nascimento de uma rede sem escala Fonte: Barabási (2002, p. 82)

A topologia sem escala "é uma consequência natural da própria natureza das redes que estão sempre em expansão. Iniciando-se de dois nós conectados entre si (acima à esquerda), em cada célula um novo nó (representado pelo círculo vazio) é adicionado à rede. Ao decidir onde vincular-se, os novos nós preferem unir-se aos nós mais conectados. Graças ao crescimento e a fixação preferencial a determinados nós, emergem centros altamente conectados [os hubs]" (Barabási, 2002, p. 82).

Concorre com esta seleção o fato de que os nós novos podem adquirir grande proeminência em pouco tempo. Páginas na web, companhias, pessoas desenvolvem certas qualidades que faz com que rapidamente cresçam o interesse por um ou uns e não por outros, a tal ponto que um pode carregar a maior parte de todos os links. É o que Barabási (2002, p. 95) identifica numa escala de fitness, isto é, "a habilidade para fazer amigos relativamente a todos os outros na vizinhança". Num ambiente altamente competitivo, os nós com maior fitness ganham links, menções e supervalorização. O modelo fitness não cobre todos os comportamentos na web, mas explica como alguns nós recém chegados ganham visibilidade exponencial rapidamente, contrariando o modelo de escala livre.

Os modelos de análise de escala livre e fitness são representações de poder, distribuído de modo desigual entre os nós que se estabelece na própria natureza da rede. De um lado, as corporações poderosas investem em apresentar determinados nós, investindo nos hubs que lhes interessam ou construindo-se como hub. De outro, criam-se certas qualidades intrínsecas aos produtos que os fazem ser desejados por milhões de internautas e vence nesta competição os que apresentam algo que captura o desejo dos consumidores. E neste caso, o vencedor leva tudo; o vencedor consegue que a maior parte de todos os links esteja apontado para ele. 
Os modelos de Barabási (2002) se endereçam à identificação de comportamentos e à natureza de nós, hubs e links na web. Os modelos de escala livre e de fitness são hábeis em tornar visível que aquilo que é caos inicialmente logo encontra ordem. Ou seja, a rede é altamente complexa, mas não é um espaço caótico, aleatório e onde tudo está visível e ao alcance de todos; potencialmente é possível pensar em visibilidade de tudo e todos, efetivamente isso não acontece.

As implicações dessas análises para o conhecimento não são exploradas por Siemens nem por Downes, embora ambos trabalhem com os conceitos de redes, conexão e caos como centrais para o conectivismo. Os autores pressupõem que a rede é livre, onde todos podem contribuir e buscar o que lhes convêm. O conhecimento estaria ao alcance de todos que poderiam criar novos e mais conhecimentos. Mas esta tese não encontra sustentação nas pesquisas de Barábasi e outros autores, o que põe em risco a própria criação de conhecimentos. Siemens e Downes optaram por uma tese mais romântica. Advogam a disposição infinita de informações, potencialmente distribuídas a todos, e as possibilidades de navegação irrestrita, o que permitiria aos internautas obter o melhor conhecimento da propriedade de realizar combinações, fusões e superposições e assim gerar conhecimentos inovadores.

Outra ideia importante para o conectivismo (Siemens, 2006) é a de que os laços fracos possibilitam aos sujeitos aprender e conhecer mais. A teoria dos laços fracos foi inicialmente trabalhada por Granovetter $(1973 ; 1983)$. Na década de 1970 há inúmeras pesquisas que contrapõem os ganhos e as perdas entre viver no âmago de laços fortes ou de laços fracos. A tese central é a de que os laços fracos, construídos nas margens das redes, em subredes e entres estas e, portanto, ao largo dos hubs, são os que promovem inovações, expansão do conhecimento, enriquecimento pessoal e coletivo.

Os laços fortes, ao contrário, são constituídos por relações endógenas nas quais os sujeitos estão encapsulados. Se de um lado, os laços fortes garantem sobrevivência imediata e proteção, de outro criam interdependência enclausurada que não permite ao sujeito sair e emancipar-se, tampouco permite a outros se acercarem. Os laços fortes formam a densidade de núcleos fechados gerando fragmentação social. Cada núcleo é encerrado em si mesmo, cria suas próprias regras e a manutenção interna de seus membros. Na outra ponta, os laços fracos permitem expansão para fora do núcleo, colocando cada sujeito em contato com outros sujeitos e núcleos, outras ideias e perspectivas que movimentam e expandem o conhecimento e as relações sociais. Destarte, geram-se novos conhecimentos que, por seu turno, geram novas relações, redes, nós e possivelmente novos hubs, o que enriquece a sociedade como 
um todo. Da perspectiva sociológica, os laços fracos engendram a democracia em oposição aos laços fortes.

Siemens e Downes incorporam intuitivamente o conceito de Granovetter (1983) ao conectivismo. Pouco esclarecem sobre o que significa isso nem demonstram através do MOOC conectivista como os laços fracos promovem mais conhecimento. São lacunas como estas que exigem pesquisas sobre as ideias que ambos reúnem, certamente cheias de insights estimulantes e inovadores para a pedagogia e quiçá para pensar uma nova teoria da aprendizagem.

Mas o que se mostra mais claramente como uma proposta pedagógica de ensinoaprendizagem (Downes, 2008), como veremos na seção sobre a pedagogia do conectivismo, é paulatinamente reivindicado como teoria da aprendizagem. E aqui começam as fragilidades mais evidentes juntamente com as críticas ao conectivismo.

\section{CONTROVÉRSIAS}

As fragilidades da proposta geram controvérsias com vários pesquisadores. Downes (2010) também se esforça para responder, mas suas respostas são tateantes, o que atribuo ao fato de o projeto do conectivismo estar em construção constantemente somando novos conceitos. Exemplo deste tateio pode ser conferido na réplica de Downes (2010, p. 86) à contraposição de Tony Foster que diz: "Estou incomodado com seu argumento de que para o conectivismo inexiste os conceitos de transferência de conhecimento e construção de conhecimento. Acredito que se o conectivismo é uma teoria de aprendizagem e não somente uma teoria sobre a conectividade, esta deveria endereçar-se à transferência de compreensão e construção da compreensão”.

Ao que Downes (2010, p. 86) responde: "Este argumento alcança o núcleo da distinção entre construtivismo e conectivismo (ao menos na minha visão)". E Downes (2010, p. 86-87) continua: "Num sistema representacional você tem uma coisa, um símbolo físico, que se coloca numa relação um a um com alguma coisa: uma porção de conhecimento, uma ‘compreensão', alguma coisa que é aprendida, etc. Em teorias representacionais falamos sobre criação ('fazer' ou 'contruir') e transferência destas porções de conhecimento. Isto é entendido como um processo que coloca em paralelo (ou nas teorias simples) a criação e a transferência de entidades simbólicas. O conectivismo não é uma teoria representacional. Não se postula a existência de símbolos físicos em relação representacional com porções de conhecimento ou compreensão. [...]. O que você está falando como 'uma compreensão' é (a melhor aproximação) distribuída em toda a rede de conexões. Conhecer que 'P' é (aproximadamente) ter um certo conjunto de conexões neurais". 
Na abordagem do conectivismo, nas palavras de Downes (2010), a personalização significa menos, ou seja, apresentam-se poucas regras e limitações aos agentes. Ele argumenta que o conectivismo envolve, sobretudo, prática nas redes. Isso é tudo o que diz a Foster e assim se encontram as respostas a outros tantos questionamentos.

Um dos problemas com as críticas nos blogues diretamente endereçadas ao conectivismo é que estão pouco desenvolvidas ou são reuniões de ideias que seus autores têm em vista esclarecer melhor. Em razão disso, a incorporação destas devem ser vistas muito mais como sinalizações de fragilidades no conectivismo. Críticas adensadas se encontram nos trabalhos de Kop e Hill (2008), Kop (2011) e Sobrino Morrás (2011). Considerando isso, destaco que as críticas registram inconformidade com a reivindicação de teoria da aprendizagem para o conectivismo.

Ryberg (2009) considera que o conectivismo traz ideias interessantes para a discussão educacional, mas ele se sente desconfortável com a afirmação de Siemens quando explica o que é distintivo no conectivismo. A afirmaçao de Siemens diz que as teorias de aprendizagem existentes falham em dar conta da expansão e criação do conhecimento. Ryberg considera, no mínimo, curioso que Siemens e Downes não refiram a teoria da aprendizagem expansiva de Yrjö Engeström. Também observa que Piaget e Vygotsky se encontram reunidos sob o mesmo rótulo: construtivismo. Embora existam similaridades entre estes teóricos, há diferenças importantes em suas abordagens. Há muitas tentativas de agrupar as teorias da aprendizagem e é difícil apresentar um panorama sobre estas sem cair em simplificações. Ryberg adverte que não é correto sugerir que as atuais teorias de aprendizagem falham em dar conta da expansão e criação do conhecimento.

Zapata (2011), em seu blog na RedCUED (2012), considera insustentável ao conectivismo apresentar-se como teoria da aprendizagem. Para ele, o que Siemens apresenta não atende às condiçâes e aos critérios destacados como essenciais para a sustentação de teorias e enfoques teóricos. Para Zapata (2011) "o certo é que o conectivismo, tal como apresenta seu autor original (Siemens, 2004), é uma interpretação de alguns dos processos que se produzem no seio da SIC [Sociedade da Informação e Comunicação], relacionados com a educação, em que se atribui um significado e uma projeção destas mudanças no âmbito da prática educativa e de sua organização".

Zapata qualifica os trabalhos de Siemens como valiosos na medida em que apresentam um ponto de vista a partir dos efeitos que produzem os entornos de aprendizagem 2.0 e seu coexistente e-learning, observando que o e-learning empresarial também move os interesses de Siemens. Ao considerar que as propostas 
de Siemens "fornecem-nos ideias de quais são as inquietações e sensiblidades de grupos acadêmicos influentes", Zapata (2011) propõe que se confronte racional e sistematicamente algumas afirmações de Siemens com teorias e ideias consolidadas na área da educação.

Para Cochrane (2011), o conectivismo situa-se melhor no que diz respeito à qualidade do acesso ao conhecimento distribuído e não sobre como o sujeito aprende. Qualidade de acesso e uso de conexões não são sinônimos de aprendizagem. Como o conectivismo inclui a separação entre significado e representação tampouco pode dizer algo sobre a aprendizagem.

Bill Kerr foi convidado por Siemens para discutir suas reservas sobre o conectivismo num evento organizado na Universidade de Manitoba em 2007. Podese ouvir o podcast com a argumentação de Kerr (2007) no qual diz que o conectvismo não é radicalmente novo e que o conceito de cognição distribuída é discutido há dez anos. Kerr (2006) resume sua posição ao dizer que "as redes são importantes, mas não mudaram a aprendizagem a tal ponto que se poderia substituir as teorias de aprendizagem estabelecidas por uma nova". Na mesma linha de abordagem de Zapata (2011), Kerr ao relacionar exigências para algo posicionar-se como teoria diz que o conectivismo não apresenta fundamentos que a sustentem atualmente neste patamar.

Kop e Hill (2008) ponderam se o conectivismo oferece uma nova teoria da aprendizagem. Os autores concluem: "Uma mudança de paradigma pode estar em curso na teoria educacional e uma nova epistemologia pode estar emergindo, mas não parece que as contribuições do conectivismo para o novo paradigma garantam que este seja tratado como outra teoria da aprendizagem. No entanto, o conectivismo tem importante papel no desenvolvimento e na emergência de novas pedagogias, nas quais o controle está saindo do tutor em direção a um aprendiz cada vez mais autônomo" (p. 11).

Sobrino Morrás (2011) endereça críticas ao conectivismo no que diz respeito à natureza da aprendizagem e do conhecimento, ao papel dos agentes e aos aspectos metodológicos. $\mathrm{O}$ autor, depois de contrapor as ideias conectivistas com a de vários autores conclui: a estrutura interconectada da informação nas redes não é um aspecto essencial da aprendizagem; a aprendizagem é uma experiência mediada pelo diálogo; a desinstitucionalização da formação carece de respaldo em pesquisa; o domínio tecnológico dos alunos não garante que sejam capazes de aproveitar as potencialidades da web 2.0; as metodologias adequadas aos novos entornos (como a aprendizagem colaborativa) devem situar-se no plano dos meios e não dos fins 
(Cf. Sobrino Morrás, 2011, p. 134). Em síntese, o conectivismo oferece uma resposta incompleta, ainda assim é a proposta pedagógica do conectivismo que recebe mais crédito, como veremos adiante.

Nas abordagens de Downes (2008), o conteúdo pedagógico do conectivismo é mais forte e visível. Diferentemente em Siemens e Conole (2011), a relevância se encontra na tentativa de propor o conectivismo como uma teoria da aprendizagem distanciando-a de teorias como o construtivismo e o cognitivismo. Siemens agrega relevâncias teóricas diferentes a cada vez que o conectivismo é retomado nos seus escritos e anotações em blogues. A insatisfação com as teorias dominantes na área do ensino-aprendizagem conduz Siemens e Downes a buscar outros paradigmas. Siemens e Conole (2011, p. iii) dizem que lhes parece "fútil discutir os méritos do conectivismo versus behaviorismo, cognitivismo ou construtivismo" numa clara referência ao artigo de Anderson e Dron (2011) no mesmo volume (Irrodl, 2011). Siemens e Conole (2011) reconhecem que o volume sobre conectivismo se mostra como uma terra confusa, na qual vicejam diferentes perspectivas sobre as quais se amparam os autores para abordar o conectivismo. E mais, os organizadores do volume (Siemens; Conole, 2011) acrescentam o mais novo conceito de "adjacente possível" de Steven Kauffman como aquele que melhor se aproxima do que eles veem na educação e conectivismo atualmente. Aqui temos mais uma ideia anunciada que é deixada para outros pesquisadores pensarem sua incorporação ao conectivismo.

Antes de trazer os argumentos de Downes (2010) é necessário registrar que a própria forma como o livro de Downes é apresentado difere daquilo que se espera. O livro é distribuído livremente pelo autor sob a licença do Creative Commons, o que é coerente e positivo quando se fala em redes e nós. Entretanto, o livro é uma bricolagem: um conjunto de registros, ideias desenvolvidas aqui e ali, comentários, respostas a outros pesquisadores, conversas entre pares, artigos apresentados em conferências, palestras, registros de aulas, postagens em blogues, etc. De um lado, esta poderia ser uma forma alternativa de trazer as ideias; de outro, esta forma é deveras difícil para o leitor trabalhar porque as ideias são rapidamente apresentadas e estão dispersas em 616 páginas. O próprio Siemens (2012) solicita a Downes apontar o que seria importante aos alunos lerem ali.

Downes (2010) tenta responder o que é e o que não é o conectivismo. Seu principal argumento é distanciar o conectivismo das teorias de aprendizagem, em especial do construtivismo e da aprendizagem ativa para citar somente aquelas com as quais os leitores de Siemens e Downes aproximam o conectivismo. O autor (Downes, 2010, p. 85) apresenta como contraposição o que segue: "Eu diria que o conectivismo difere destas teorias ao negar que o conhecimento é proposicional. Isto é, estas teorias são 
'cognitivistas' no sentido de que elas representam o conhecimento e a aprendizagem como tendo base na linguagem e na lógica”.

Por contraste, o autor argumenta que "o conectivismo é coneccionista [...]. O conhecimento é, nesta teoria, literalmente o conjunto de conexões formadas por ações e experiência. Pode-se dizer que se constitui, em parte, em estruturas linguísticas. As propriedades e as limitações das estruturas linguísticas não são as propriedades e as limitações do conectivismo ou do conhecimento conectivista [...] conexões formam-se naturalmente através de um processo de associação e não são 'construídas' através de algum tipo de ação intencional” (Downes, 2010, p. 85).

Downes (2010) segue marcando outras diferenças, entre as quais a de que o conectivismo não se traduz por transferir ou construir conhecimento. O conectivismo trata de desenvolver os sujeitos e a sociedade de um modo conectado. Segundo o autor, isto implica numa pedagogia específica que descreve as redes, identificadas por suas propriedades: diversidade, autonomia, abertura e conectividade. A pedagogia derivada do conectivismo descreve as práticas que organizam e direcionam a aprendizagem e o conhecimento nas redes (Downes, 2008). O autor entende que a participação do professor se caracteriza como modelagem e demonstração e a participação do aluno como prática e reflexão. Não há maior detalhamento sobre este entendimento que carateriza a ação de ambos nos cursos conectivistas. Entretanto, a prática pedagógica descrita por Downes (2008) é coerente com as ideias sobre conectivismo e por isso, a meu ver, é a abordagem pedagógica que tem efetivamente relevância no conjunto dos escritos de Downes. Resta-nos acompanhar os desdobramentos destas práticas, em especial com as propostas na modalidade Massive Open Online Courses (MOOC), para desenvolver a teoria de uma prática pedagógica, seus impactos sobre alunos e professores e seus efeitos sobre as aprendizagens.

\section{A PEDAGOGIA DO CONECTIVISMO}

Downes (2008) mostra como ele e Siemens traduziram o conectivismo e o conhecimento conectado numa prática pedagógica. Downes registra que este é o primeiro curso explicitamente planejado de acordo com os princípios do conectivismo. O curso Connectivism \& Connective Knowledge desenvolvido em 2008 (CCKo8) ofertado na modalidade Massive Open Online Course (MOOC) atendeu 25 alunos matriculados e mais 2200 pessoas que se inscreveram para participar. O que distingue o curso é o número expressivo de participantes e, sobretudo, a concepção pedagógica baseada na ideia de que "o conhecimento é distribuído através da rede de conexões e a aprendizagem consiste na habilidade de construir e estudar nestas 
redes" (Downes, 2008, p. 2). Em mais recente trabalho, Downes (2012, p. 9) diz que "aprendizagem é a criação e a remoção de conexões entre as entidades ou o ajustamento das forças dessas conexões". A aprendizagem e o conhecimento nesta pedagogia não são gerados a partir de objetivos externos, propostos por outros. A Figura 2, incorporada no artigo de Downes (2008, p. 1), mostra um mapa das conexões entre os diferentes elementos e ferramentas digitais presentes no curso. A figura é um tanto confusa, mas se a aproximarmos é possível distinguir a interrelação de muitos elementos no curso, o que representa um desafio para os participantes em acompanhá-lo.

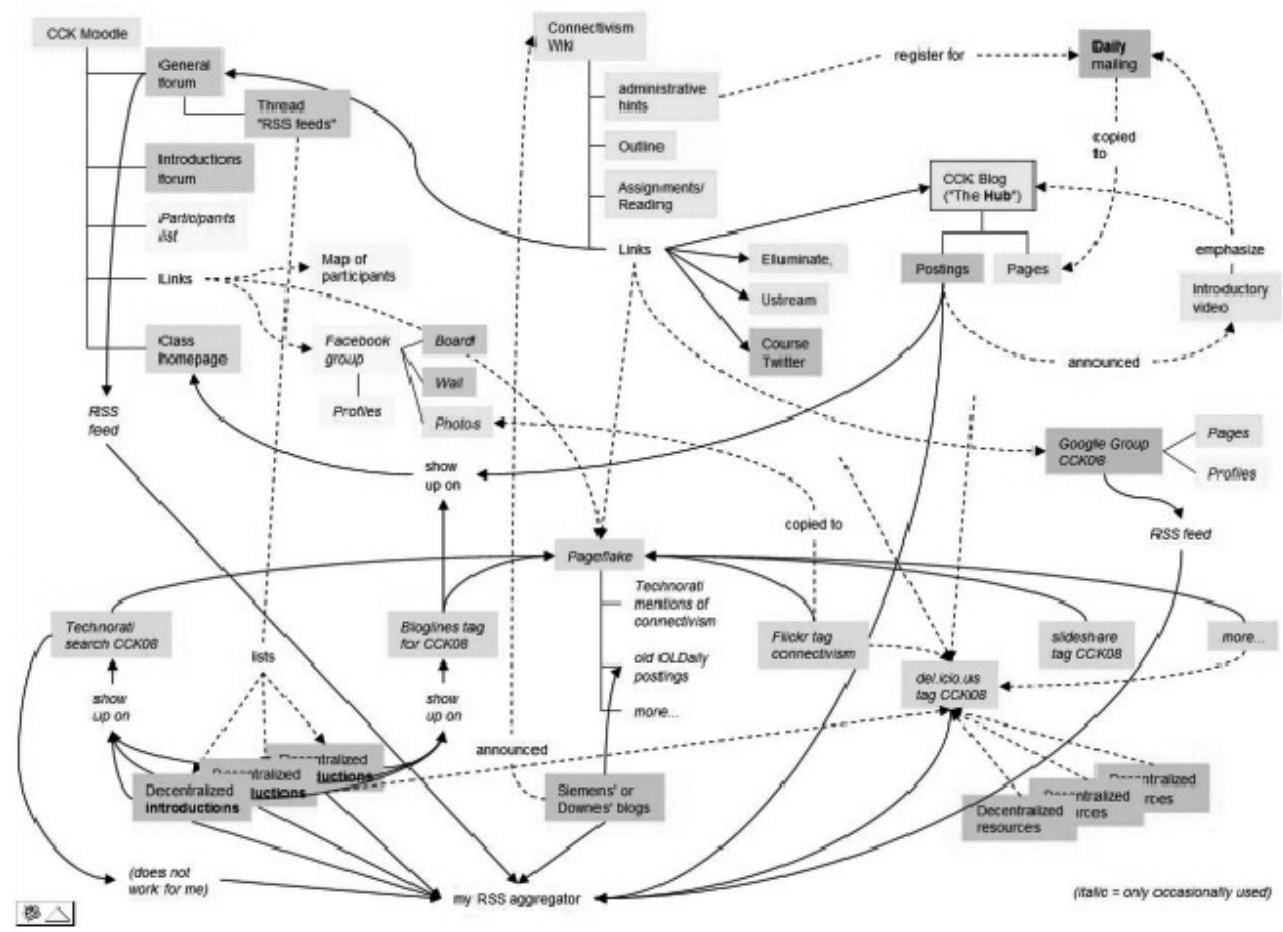

Figura 2. CCKo8: A estrutura de um MOOC conectivista

Fonte: Downes (2008, p. 1)

As características distintivas do MOOC/CCKo8 são:

- A ênfase do curso é na diversidade e na conectividade. Resulta, na prática, a determinação de um ponto de partida, mas sem a determinação do ponto de chegada. Nesta pedagogia não é possível estabelecer os mesmos objetivos para 
todos. Cada aluno elege o que lhe interessa da proposta e a partir disso define o seu entorno de aprendizagem. Os investimentos resultam em diferentes objetivos, múltiplos caminhos e, supostamente, novos conhecimentos são gerados por fusão e superposição. Nem mesmo é possível a um aluno, aos grupos de participantes ou à equipe docente acompanhar tudo o que se passa no curso. Os participantes são encorajados a fazer suas próprias escolhas, o que, segundo Downes (2008), ajuda-os a desenvolver perspectivas únicas que são incorporadas na conversação.

- Os processos pedagógicos são descentralizados. Isso significa que cada agente ou grupo de agentes põem em movimento formas distintas de aprender e cooperar entre si. Os participantes criam seus próprios grupos de discussão, desdobrando a temática central. As ferramentas digitais e as formas de conduzir a disciplina são tanto propostas pelos professores como pelos participantes. Esta proposta cria uma profusão de grupos, de subtemáticas, de encaminhamentos e de postagens em diferentes ferramentas (blogues, wikis, twitter, facebook, foruns dentro e fora do moodle, grupos e espaços no Second Life, listas diversas, etc.). Para que alunos, participantes e equipe docente não se percam na abundância de informação gera-se um hub, ou seja, todas as criações estão remetidas ao blogue do MOOC/CCKo8. Outra forma para localizar a todos foi o uso de boletim informativo diário por correio eletrônico e uso de RSS que informou o movimento de todos em todas as ferramentas digitais. Há atividades comuns, poucas, como ler as postagens dos professores, assistir as conferências online e os alunos que se matricularam realizam uma atividade de avaliação, como a produção de um artigo.

- Os processos administrativos são igualmente descentralizados. Esta proposta permite a um grande número de participantes realizar o curso, o que é uma característica dos MOOC em geral. Não há pré-requisito para participar e tem-se alunos matriculados ao lado de outros tantos que somente participam no curso. A acreditação pode ser pela própria universidade ou por outra. Mas o mais comum é a maior parte dos alunos participar sem buscar acreditação.

A realização desta pedagogia, deste modo, na rede exige alto grau de comprometimento e de autodeterminação dos participantes. Não há como avaliar o conhecimento de cada um ou de cada grupo nesta modalidade, porque a marca é a dispersão de pessoas, grupos e temáticas em muitas e distintas ferramentas digitais. Qual é o impacto real disso sobre a aprendizagem não se sabe e, talvez, não se consiga derivar a aprendizagem efetiva de alunos e participantes a partir do que é feito no curso, salvo se nos detivermos em estudar caso a caso. Mas não é o propósito 
dos autores realizar isso, tampouco propor uma avaliação como em geral se realiza. Os próprios autores (Siemens e Downes) solicitam ao aluno matriculado (que são poucos) um artigo final para dar conta da avaliação institucional.

Os MOOC que investem no uso das tecnologias digitais como ponte entre os sujeitos e saberes apresentam outra concepção sobre a pedagogia e a aprendizagem. São os sujeitos que assumem a responsabilidade e a tarefa de investir na sua formação. Esta modalidade de curso não se encaixa nos cânones acadêmicos tradicionais, nem mesmo se adequa para todos os alunos, participantes ou professores, como veremos na sequência. Todavia, esta modalidade e sua correspondente compreensão pedagógica configuram-se como outra possibilidade de realizar a aprendizagem e o conhecimento. Não perpassa a proposta conectivista nem as práticas nos MOOC pôr fim aos modos tradicionais de se educar as pessoas. Os diferentes modos de aprender, a diversidade de pessoas e experiências que circulam na rede e a distributividade do conhecimento são benéficos para todos, como sugerem os autores aqui reunidos.

\section{ÊNFASES CONECTIVISTAS EM OUTROS CURSOS}

Kop (2011) analisa a abordagem do conectivismo aplicada no desenvolvimento de duas disciplinas na modalidade MOOC em 2010. A organização pedagógica implica em que os participantes devem lidar com a complexidade dentro de um ambiente minimamente estruturado, envolvendo-se e responsabilizando-se por sua aprendizagem pessoal e coletiva. O curso exige do participante movimentar-se com certa desenvoltura no uso de muitas ferramentas digitais e entre diferentes artefatos criados por um grupo numeroso de participantes em cada disciplina.

Os resultados da análise de Kop (2011) mostram que a abordagem conectivista aplicada no desenvolvimento de cursos MOOC não se cumpre inteiramente. Os participantes mais jovens, em especial aqueles sem experiência anterior com o MOOC, sentem-se confusos e perdidos com incontáveis recursos e contribuições de todos os lados. A natureza das atividades no MOOC, as ações e respostas distribuídas causam ansiedade em quem se insere pela primeira vez na experiência.

O autodirecionamento é bem-vindo por alguns e um ponto crítico para outros que preferem coordenação e tarefas que deem direção à sua aprendizagem. Esses participantes manifestam que necessitam sentir-se confortáveis, acolhidos e confiantes para participar, ou seja, desejam estar presentes numa comunidade. Eles destacam a proximidade, a discussão focada e a retroalimentação como essenciais para o engajamento e a aprendizagem em profundidade. Este é um ponto que contradiz a ideia de Siemens (2005) de que os laços fracos produzem mais conhecimento; o que 
Siemens propõe não encontra o que sente e demanda uma parte de alunos. Retorno a este ponto adiante.

Outros se sentem confortáveis, pois produzem, agenciam grupos, buscam e conseguem colaboração para seus projetos, embora não exista a informação precisa do seu perfil. No entanto, sabe-se que os participantes ativos e confortáveis são em número inexpressivo, pois de 1610 alunos somente entre 40 e 60 alunos participaram regular e ativamente. A autora (Kop, 2011) observa que o fato de a maior parte dos estudantes ter mais de 55 anos, ser profissionalmente estabelecida e investir no seu autodesenvolvimento leva-os a serem autonômos e a se sentirem confortáveis com a abordagem conectivista no MOOC comparativamente aos estudantes jovens. Mesmo assim, a autora conclui que é necessário tempo para que os alunos se envolvam com as atividades e tempo para que eles possam digerir as informações e produzir nesta proposta.

Mackey e Evans (2011) propõem-se analisar as interconexões na rede para a aprendizagem da prática profissional de professores do ensino básico. Os autores examinam os processos de interação entre professores que cursam disciplinas online de pós-gradução em Tecnologias da Informação e Comunicação (nos anos de 2005 a 2008). Também, entrevistam professores fora do programa de pós-graduação, mas colegas de trabalho dos primeiros. O conceito que move a pesquisa é o de comunidade de prática de Wenger. E o foco se centra na amplitude de influência que os professores em formação levam para suas comunidades de prática, criando continuidades entre fronteiras. Adicionalmente, os autores abordam a perspectiva conectivista, em especial o conceito de cognição distribuída, através da qual os professores criam e ampliam conhecimento coletivamente.

Os resultados (Mackey e Evans, 2011) indicam que as atitudes são pragmáticas ao relacionar ideias e práticas no curso com as aplicações práticas cotidianas. $\mathrm{O}$ contexto de inserção de cada sujeito modifica sua ação nas comunidades de prática. Uma das professoras mais ativas no curso era novata na escola, o que fez ela se movimentar com restrições; sua ação na escola se dirigia a um grupo pequeno de professores. O efeito mais evidente é a aplicação de ideias e uso da web 2.o junto aos próprios alunos. Da perspectiva conectivista, os professores consideram útil as interações online, mas eles não formam laços fortes. Eles relatam sentirem-se desafiados a pensar e propor alternativas a partir das discussões, contrapontos, experiências e pontos de vista compartilhados na rede com outros professores. Este comportamento encontra a teoria sociológica dos laços fracos de Gravenotter (1983), também incorporado ao conectivismo por Siemens (2005). 
Entretanto, as pesquisas mostram diferentes resultados e indicações para a mesma questão de prescindir ou não de uma comunidade para aprender. Nas pesquisas de Kop (2011), os laços fortes são importantes para a aprendizagem e para expandir o conhecimento, ao menos para um grupo de alunos. A pesquisa de Mackey e Evans (2011) aponta para os laços fracos. Temos aqui um ponto controvertido para o qual necessitamos pesquisa que distinga o que contribui para a expansão do conhecimento individual e coletivo: se os laços fracos ou os laços fortes. Se ambos contribuem, quando, como e em que medida um ou outro se fazem mais evidentes nos seus efeitos sobre a ampliação do conhecimento construído nas redes online.

Granovetter (1983, p. 209) apresenta discussões que ajudam no entendimento deste ponto controverso. O autor diz: "Os laços fracos oferecem às pessoas acesso à informação e aos recursos para além daqueles disponíveis no seu próprio círculo social; mas os laços fortes dispõem de grande motivação para ajudar e estão mais facilmente disponíveis”. Uma das vantagens dos laços fracos é a oportunidade de ganhar informações novas através de associação com outras pessoas fora círculo mais próximo. O que, conforme Gravenotter (1983), é potencializador em criar, ampliar e disseminar conhecimentos.

A predisposição em ajudar contida na comunidade e sua carecterística de estar à mão oferecem apoio e proteção àqueles que buscam e sentem-se mais acolhidos e confortáveis em se movimentar no seio de laços fortes (Bauman, 2003) ${ }^{3}$. Entretanto, mesmo as pessoas que se amparam mais em laços fortes, cedo ou tarde, serão obrigadas a transitar entre pessoas e redes com laços fracos. Na outra ponta, as pessoas que consideram mais útil transitar por laços fracos podem encontrar constrangimentos sociais que as obriguem a fazer uso de laços fortes. Mas estes últimos parecem estar cada vez mais escassos no mundo líquido (Bauman, 2003). Trata-se, então, de analisar quais são os fatores que afetam estas variações e em que situações ou para quais sujeitos os laços fortes ou fracos funcionam melhor. Gravenotter (1983) adverte que a concentração das energias em laços fortes tem como impacto a fragmentação social, encapsulando os sujeitos em redes com conexões pobres. Os indivíduos encapsulados podem perder as vantagens associadas à riqueza contida nos laços fracos.

Da perspectiva pedagógica, os alunos desconfortáveis com a dispersão, a diversidade, o autodirecionamento, presupostos nos laços fracos dos MOOC precisarão encontrar amparo em comunidades. Tal como ocorreu com grupos no MOOC/CCKo8 de Siemens e Downes; alguns participantes criaram um subgrupo no Second Life para sentir-se participante de uma comunidade, mesmo que o preço desta necessidade momentaneamente resulte em menor amplitude de conhecimento. 
A crítica de Bauman (2003) encontra muitas das ideias de Gravenotter (1983) vinte anos depois, bem como os insights de Siemens e Downes. Bauman (2003, p. 132-133) lembra-nos o tempo todo sobre o estado das relações no mundo líquido: "O que vemos pode prometer prazer, mas também pode anunciar perigo; quando apenas superfícies se encontram (e sempre 'de passagem') há poucas chances de se negociar o que é o quê. $\mathrm{E}$ a arte de viver numa multidão de estranhos impede que essa chance se materialize - deter o encontro antes que ele mergulhe além da superfície é o mais comum dos estrategemas. [Ao mesmo tempo] somos todos interdependentes neste nosso mundo que rapidamente se globaliza, e devido a esta interdependência nenhum de nós pode ser senhor do seu destino por si mesmo".

Não há caminho fácil para os que participam da pedagogia proposta pelos MOOC, pois as exigências são grandes quanto a tomar para si incontáveis decisões, ou seja, é a personalização maximizada das tarefas que envolvem a aprendizagem. Alguns se sentem confortáveis com os laços fracos e transitam com desenvoltura nesta pedagogia ultramaleável, mas são aqueles que desfrutam de certas condições: experiência e, provavelmente, conquistas pessoais-profissionais; outros, na sua maioria os mais jovens, demandam mais atenção, direcionamento e proximidade que somente os laços fortes nas comunidades podem oferecer se eles conseguirem autodirecionar-se para propô-las e sustentá-las. Permanecem dúvidas se fazer parte de comunidades é suficiente para os mais jovens aprenderem e conhecerem. Caso os mais jovens demandem mais atenção, direção e retroalimentação, as pedagogias abertas e ultramaleáveis podem não ajudá-los como desejariam ou necessitariam para desenvolver um "bom trabalho", no sentido que lhe atribui Gardner (2012).

\section{CONCLUSÕES}

O conectivismo atribui relevância às novas condições e ecologia de aprendizagem que envolvem abundância de informação, redes e conectividade. Sua emergência é em contexto de caos, mudanças rápidas e diversidade. O conhecimento é definido como o reconhecimento de padrões particulares de relações que ocorrem na rede entre nós. A aprendizagem é definida como a criação de novas conexões. O modelo representacional da aprendizagem é o do cérebro e suas conexões neurais. Há inúmeros conceitos agregados à proposta conectivista e aqui detenho-me em redes e laços.

Os teóricos das redes analisam a internet como espaço complexo no qual a distribuição de nós e hubs é desigual nas escalas livre e fitness. Para o conectivismo a rede distribui livremente informações e dados. Os conhecimentos inovadores advem 
da propriedade de realizar combinações, fusões e superposições. Mas esta é uma premissa insustentável dada a natureza das escalas na rede.

Os laços fortes constituídos por relações endógenas encapsulam os sujeitos. Os laços fracos permitem expansão das relações sociais e do conhecimento. Para o conectivismo, os laços fracos têm relevância, mas as análises mostram que ambos têm papel a desempenhar no esforço de quem aprende.

As críticas ao conectivismo registram inconformidade com sua reivindicação de teoria da aprendizagem. A melhor aceitação ao conectivismo se encontra no seu enderaçamento à pedagogia. A ênfase dos cursos é na diversidade e na conectividade, criando-se inúmeros grupos, subtemáticas e encaminhamentos.

A organização pedagógica conectivista implica que os participantes devem lidar com a complexidade dentro de um ambiente minimamente estruturado. $\mathrm{O}$ autodirecionamento e os laços fracos são bem-vindos por alunos experientes e pontos críticos para os mais jovens, que demandam coordenação e convivência em comunidades.

\section{NOTAS}

1. Em geral, os artigos destacam os princípios do conectivismo (Siemens, 2004; 2005). Em 2004, Siemens apresenta seis princípios, mas em 2005 ele passou a chamar os princípios de atributos, esclarecendo: “A aprendizagem em rede é um subconjunto do conectivismo. Ao apresentar a original teoria do conectivismo, apresento oito atributos: (1) A aprendizagem e o conhecimento repousam na diversidade de opiniões; (2) A aprendizagem é um processo de conectar nós especializados ou fontes de informação; (3) A aprendizagem pode residir em dispositivos não humanos; (4) A capacidade de saber mais é mais importante do que aquilo que sabemos num determinado momento; Promover e manter conexões é necessária para facilitar a aprendizagem contínua; (5) A capacidade de ver conexões entre ideias, conceitos e áreas de saber é uma competência central; (6) A manutenção em circulação de conhecimento atualizado e rigoroso é o objetivo de todas as atividades de aprendizagem conectivistas; (7) A tomada de decisões é, em si mesma, um processo de aprendizagem; (8) Escolher o que aprender e o sentido da informação que nos chega é visto através da lente de uma realidade em permanente transformação. A resposta correta de hoje pode ser a errada de amanhã, devido a alterações no clima informacional que afeta as decisões". O autor acrescenta aos atributos a afirmação de que a aprendizagem em rede se relaciona em grande medida com o segundo princípio do conectivismo: a formação de redes. Estas ideias gerais sobre conectivismo estão presentes em 2004 e 2005. Entretanto, a proposta do conectvismo foi ganhando novos contornos e uma infinidade de conceitos são, paulatinamente, nomeados como importantes. 
2. A ideia dos seis graus de separação é levantada por Milgram (1967, p. 62) quando ele pergunta: "Partindo de duas pessoas aleatoriamente selecionadas no mundo, qual é a probabilidade delas virem a se conhecer? Uma formulação mais sofisticada levaria em conta o fato de que as pessoas $\mathrm{X}$ e $\mathrm{Z}$ podem não conhecer-se diretamente, mas elas poderiam compartilhar um amigo comum, ou seja, uma pessoa que conhece a ambos. Pode-se pensar numa corrente de amigos com X conhecendo Y e Y conhecendo Z". Conferir os vídeos (BBC, 2012).

3. Mesmo que a comunidade seja um conceito e uma vivência da modernidade sólida, Bauman (2003, p. 129) diz que "sentimos falta da comunidade porque sentimos falta de segurança. Qualidade fundamental para uma vida feliz, mas que o mundo que habitamos é cada vez menos capaz de oferecer e mais relutante em prometer".

\section{REFERÊNCIAS BIBLIOGRÁFICAS}

Athabasca University (2011). IRRODL. International Review of Research in Open and Distance Learning, 12 (3), Manitoba, Canadá. [en línea] Disponible en: http://www.irrodl.org/index.php/irrodl/issue/view/44 [consulta 2012, 21 de noviembre].

Barabási, A. L. (2002). Linked: the new science of networks. How everything is connected to everything else and what it means. Cambridge, MA: Perseus Publishing.

Bauman, Z. (2003). Comunidade: a busca por segurança no mundo atual. Rio de Janeiro: Zahar.

BBC (2010). Seis graus de separação. [en línea] Disponible en: http://www.youtube.com/watch?v=pz29Onl uRw [consulta 2012, 10 de diciembre].

Cochrane, G. (2011). Why Connectivism is not a learning theory. Blog A Point of Contact. [en línea] Disponible en: http://apointofcontact.wordpress. com/2011/09/07/why-connectivism-isnot-a-learning-theory/ [consulta 2012, 5 de diciembre].

Downes, S. (2008). Places to go: connectvism \& connective knowledge. Innovate. Journal of Online Education, 4 (6), (1-6). Nova Southeastern University. [en línea] Disponible en: http://www. innovateonline.info/pdf/vol4 issue6/
Places to Go- Pedagogy in Action. pdf [consulta 2012, 21 de noviembre].

Downes, S. (2010). Connectivism and connective knowledge: essays on meaning and learning networks. National Research Council Canada. Published under a Creative Commons License.

Gardner, H. (2012). Educating digital youth and nurturing good work. [en línea] Disponible en: http://vimeo. com/55545080 [consulta 2012, $28 \mathrm{de}$ diciembre].

Granovetter. M. (1973). The strength of weak ties. American Journal of Sociology, 78 (6), (1360-1380).

Granovetter, M. (1983). The strength of weak ties: a network theory revisited. Sociological Theory, 1, (201-233).

Kerr, B. (2006). A challenge to connectivism. [en línea] Disponible en: http:// billkerr2.blogspot.com.es/2006/12/ challenge-to-connectivism.html [consulta 2012, 05 de octubre].

Kerr, B. (2007). My argument against connectivism. [en línea] Disponible en: http//www2.franciscan.edu/jcoyle/ media/OCC B Kerr 07Feb2007.mp3 [consulta 2012, 15 de octubre].

Kop, R. (2011). The chalenges to connectivist learning on open online networks: learning experiences during a massive Open Online Course. IRRODL, International 
Review of Research in Open and Distance Learning, 12 (3), (19-37).

Kop, R.; Hill, A. (2008). Connectivism: learning theory of the future or vestige of the past? IRRODL, International Review of Research in Open and Distance Learning, 8 (3), (1-13).

Lévy, P. (1996). O que é virtual? Rio de Janeiro: Editora 34.

Milgram, S. (1967). The small world problem. Psychology Today. 1 (1), (61-67).

Ryberg, T. (2009). Connectivism wiki and the creation of knowledge. [em línea] Disponible en: http://ryberg.blog.hum. aau.dk/tag/connectivism/ [consulta 2012, 05 de septiembre].

Santamaría, F. (2010). Introducción. La era conectiva: por el desorden natural de los artefactos y nodos. In Siemens, G. (2004). Connectivism: a learning theory for the digital age. [en línea] Disponible en: http://www.elearnspace. org/Articles/connectivism.htm [consulta 2012, 30 de octubre].

Siemens, G. (2005). Connectivism: learning as network-creation. [en línea] Disponible en: http://www.elearnspace.org/ Articles/networks.htm [consulta 2012, 30 de octubre].

Siemens, G. (2006). Knowing Knowledge. [en línea] Disponible en: http://www. elearnspace.org/KnowingKnowledge LowRes.pdf [consulta 2012, 25 de octubre].

Siemens, G. (2008). Connectivism. [en línea] Disponible en: http://www.connectivism.ca/?p=116 [consulta 2012, 21 de noviembre].

Siemens, G. (2010). Conociendo el conocimiento. Traducción de Emilio Quinta- na, David Vidal, Lola Torres y Victoria A. Castrillejo. [en línea] Disponible en: http://www.nodosele.com/conociendoelconocimiento/ [consulta 2012, 25 de octubre].

Siemens, G. (2012). Connectivism: Downes on connectivism and connective knowledge. [en línea] Disponible en: http://www.connectivism.ca [consulta 2012, 12 de diciembre].

Siemens, G.; Conole, G. (2011). Editorial. IRRODL, International Review Of Research In Open And Distance Learning, 12 (3), (i-iv) [en línea] Disponible en: http://www.irrodl.org/index.php/ irrodl/article/view/994/1831 [consulta 2012, 23 de noviembre].

Sobrino Morrás, A. (2011). Processo de enseñanza-aprendizage y web 2.0: valoración del conectivismo como teoría de aprendizaje post-constructivista. Estudios Sobre Educación, 20 (117-140) [en línea] Disponible en: http://dspace.unav. es/dspace/bitstream/10171/18344/2/ ESE\%20117-139.pdf [consulta 2012, 10 de enero].

Watts, D. J. (2003). Six Degrees: the science of a connected age. New York e London: W.W. Norton \& Company.

RedCUED. (2012). De la Cátedra UNESCO de Educación a Distancia. [en línea] Disponible en: http://redcued.ning. com/ [consulta 2012, o9 de diciembre].

Zapata, M. (2011) ¿Es el "conectivismo" una teoría? ¿Lo es del aprendizaje? [en línea] Disponible en: http://blogcued. blogspot.com.es/2011/o9/es-el-conectivismo-una-teoria-lo-es-del.html [consulta 2012, 09 de diciembre].

\section{PERFIL ACADÉMICO Y PROFESIONAL DE LA AUTORA}

Marie Jane Soares Carvalho. Professora Associada do Departamento de Ensino e Currículo, Faculdade de Educação/UFRGS. Doutora em Educação. Coordenadora do Centro de Formação Continuada de Professores da Educação 
Básica. Coordenação do Núcleo de Estudos em Tecnologias Digitais na Educação. Membro de grupos/CNPq: Inclusão Digital (UPF) e Tempo Sociedade (UFMG). Trabalha com linhas de pesquisa em: Currículo e Educação a Distância. Estudos da cibercultura. Tecnologias e metodologias de inclusão digital. Formação de Professores. Temporalidades e Gênero.

E-mail: marie.jane@ufrgs.br

DIRECCIÓN DE LA AUTORA

Universidade Federal do Rio Grande do Sul

Faculdade de Educação/Departamento de Ensino e Currículo

Av. Paulo Gama, s/n. Prédio 12201

Sala 700-07, $7^{\circ}$ andar

Bairro Farroupilha

90049-060 - Porto Alegre, RS - Brasil

Fechas de recepción del artículo: 15/12/12

Fecha de aceptación del artículo: 13/04/13

\section{Como citar este artículo:}

Soares Carvalho, M. J. (2013). Proposições e controvérsias no conectivismo. RIED. Revista Iberoamericana de Educación a Distancia, volumen 16, $\mathrm{n}^{0}$ 2, pp. 09-31. 